\title{
Recurrent Chylothorax in Renal Cell Carcinoma
}

\author{
Moeezullah Beg ${ }^{1}$, Hamza Arif ${ }^{2}$ \\ 1. Internal Medicine, University of Texas Health Science Center at San Antonio, San Antonio, USA 2. Geriatric \\ Medicine, University of Pittsburgh Medical Center St. Margaret, Pittsburgh, USA
}

Corresponding author: Moeezullah Beg, beg@uthscsa.edu

\section{Abstract}

Chylothorax is a type of pleural effusion that results from the build up of chyle in the pleural space. Trauma and malignancies are its leading causes. Among malignancies, lymphomas cause the majority of chylothoraces. A few cases of chylothorax resulting from various solid malignancies have been reported in the literature but renal cell carcinoma (RCC) has been rarely associated. Here, we report a rare case of a unilateral chylothorax associated with a newly diagnosed RCC.

Categories: Urology, Oncology, Pulmonology

Keywords: chylothorax, pleural effusion, renal cell carcinoma, malignancy associated chylothorax.

\section{Introduction}

Chylothorax is a type of exudative pleural effusion that results from lymphatic fluid build-up in the pleural space. It can be broadly classified as traumatic and non-traumatic, with equal reported incidence [1]. Malignancies, particularly lymphomas, are the leading cause of non-traumatic chylothoraces [1-2]. A few cases of chylothorax resulting from various solid malignancies have been reported in the literature but renal cell carcinoma (RCC) has been rarely associated. Here, we present a unique occurrence of a unilateral chylothorax associated with a newly diagnosed RCC.

A part of this article was presented at the American Thoracic Society International Conference 2017 (Poster: Beg M, Arif H, Young M, Alhassan S, Bihler E. A case of recurrent chylothorax in renal cell carcinoma. American Thoracic Society 2017 International Conference; 2017: 19-24).

\section{Case Presentation}

A 61-year-old, morbidly obese gentleman presented with worsening dyspnea on exertion without any associated fever, chills, cough, or chest pain. Physical examination was unremarkable except for diminished breath sounds over the right lung. Laboratory investigations, including complete blood count and comprehensive metabolic panel, did not reveal any abnormalities. Chest radiography showed a right-sided opacity suggestive of pleural effusion (Figure 1) and computed tomography (CT) of the chest revealed a

Received 05/31/2019

Review began 07/14/2019 Review ended 07/16/2019 Published 07/22/2019

(c) Copyright 2019

Beg et al. This is an open access article distributed under the terms of the Creative Commons Attribution License CC-BY 3.0., which permits unrestricted use, distribution, and reproduction in any medium, provided the original author and source are credited. moderate-sized right-sided pleural effusion (Figure 2).

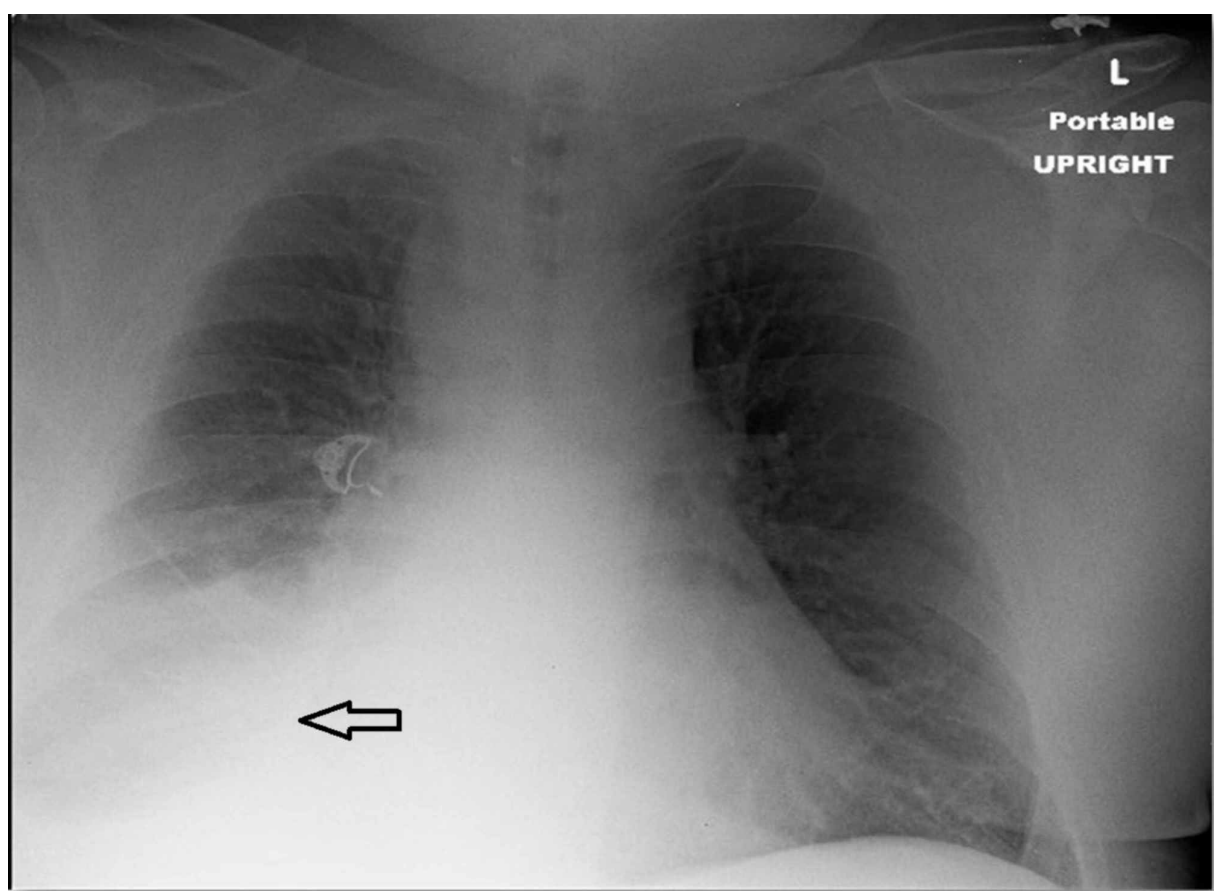




\section{Cureus}

\section{FIGURE 1: Initial chest X-ray showing right-sided pleural effusion}

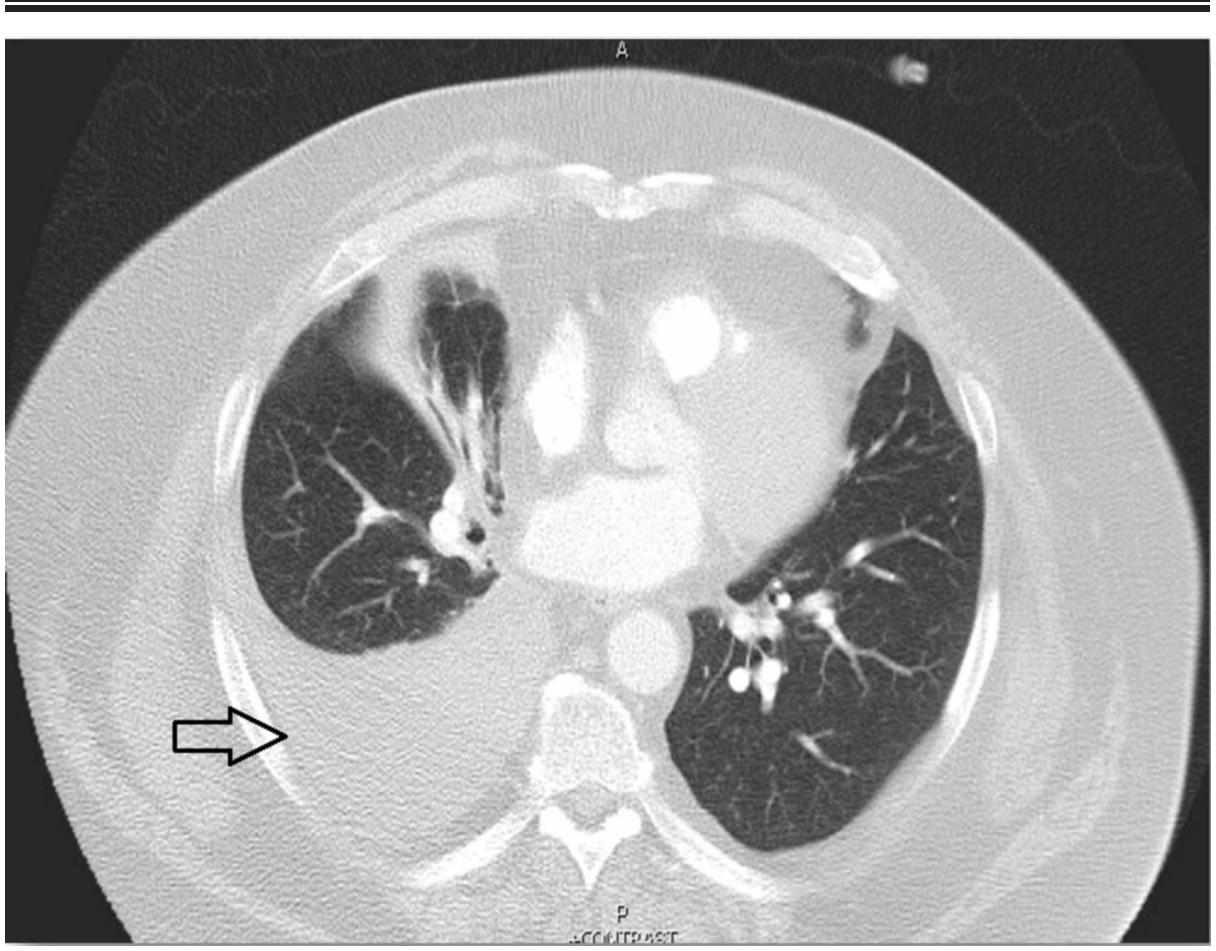

FIGURE 2: Computed tomography chest showing right-sided pleural effusion

The next day, he underwent diagnostic thoracentesis followed by a small-bore chest tube. Pleural fluid analysis (Table 1) showed an exudative effusion with cholesterol of $158 \mathrm{mg} / \mathrm{dl}$, triglycerides of $541 \mathrm{mg} / \mathrm{dl}$, a total white blood cell (WBC) count of 3825/mcl with $96 \%$ lymphocytes predominance. Pleural fluid gram stain and culture were negative.

\begin{tabular}{|l|l|}
\hline Trait & Value \\
\hline Appearance & Yellow \\
\hline Protein $(\mathrm{g} / \mathrm{dL})$ & 4.7 \\
LDH $(\mathrm{U} / \mathrm{dL})$ & 124 \\
Triglycerides $(\mathrm{mg} / \mathrm{dL})$ & 541 \\
Cholesterol $(\mathrm{mg} / \mathrm{dL})$ & 158 \\
WBCs per microliter & 3825 \\
\hline Percent lymphocytes & $96 \%$ \\
\hline
\end{tabular}

\section{TABLE 1: Pleural fluid analysis}

LDH, lactate dehydrogenase; WBC, white blood cells.

Fluid cytology showed atypical lymphocytes and reactive mesothelial cells, and flow cytometry of the pleural fluid did not show any immunophenotypic findings diagnostic of granulocytic sarcoma or non-Hodgkin's lymphoma. 


\section{Cureus}

recurred and he returned to the hospital five days later with complaints of progressively worsening shortness of breath. Repeat chest radiography showed findings consistent with recurrent right pleural effusions. Upon further investigation, a solid, enhancing, $4.9 \mathrm{~cm}$ right renal mass without associated lymphadenopathy was discovered on CT of the abdomen (Figure 3).

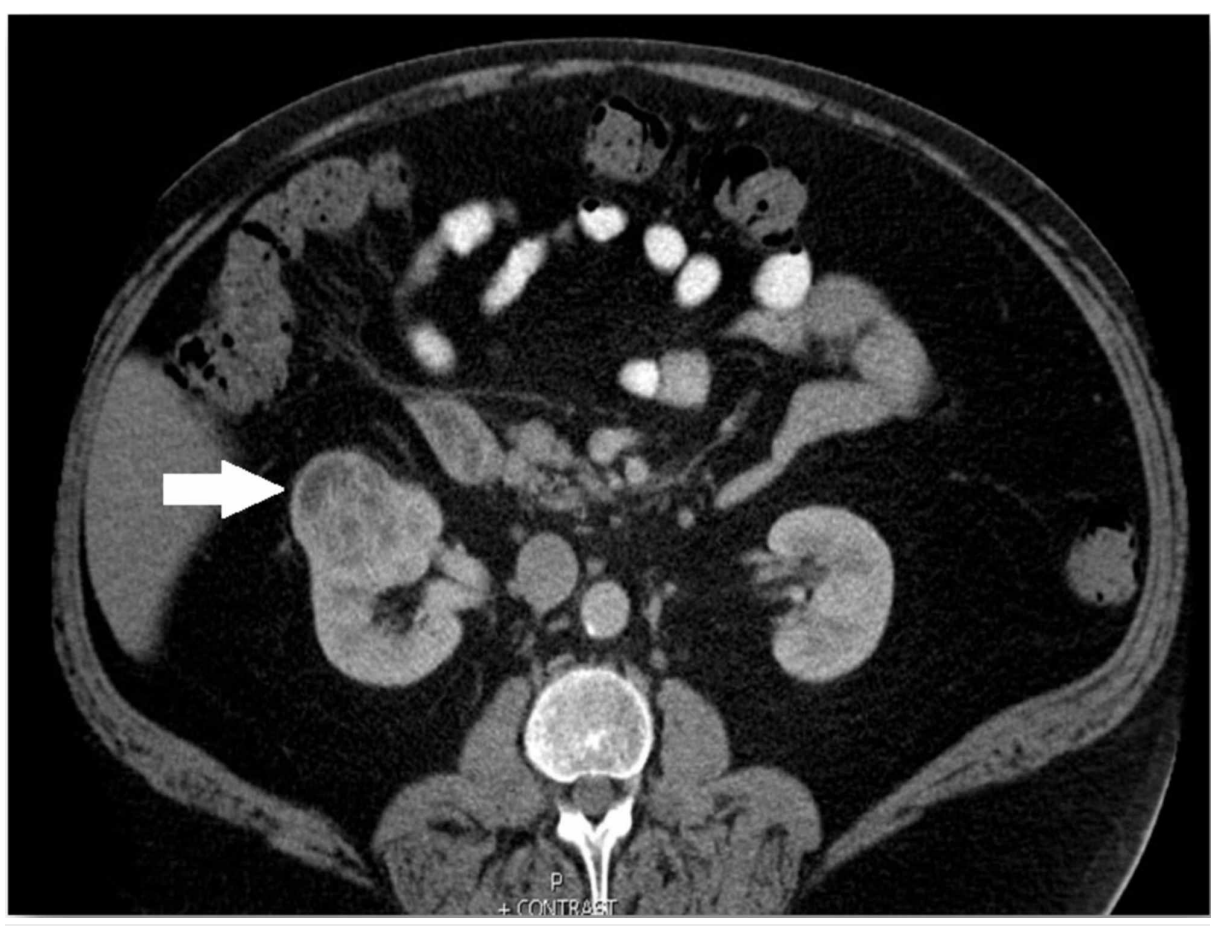

\section{FIGURE 3: Computed tomography abdomen showing an exophytic mass originating from upper lateral aspect of the right kidney}

RCC was diagnosed with a biopsy and was treated with microwave ablation, as the patient was a poor surgical candidate. This led to the resolution of his recurrent chylothorax.

\section{Discussion}

Chylothorax is characterized by the presence of chyle in the pleural space. Chyle is the lymphatic fluid primarily composed of triglycerides absorbed from the gastrointestinal tract. It is carried from the cisterna chyli in the abdomen to the central venous circulation by the thoracic duct [1]. Any disruption in the function or structure of the thoracic duct can lead to chylothorax.

Chyle is a milky-appearing fluid, which is usually exudative in character, but it may be transudative in up to $10 \%$ of cases [2]. The pleural fluid triglyceride level is a useful test for diagnostic purposes, as a level greater than $110 \mathrm{mg} / \mathrm{dl}$ is a highly specific finding for this condition [3].

Although the diagnosis of chylothorax is usually not difficult, determining its etiology can be a challenge. Broadly, chylothorax can be classified as traumatic and non-traumatic. Malignancy is the most commonly described disorder for non-traumatic causes [4] with lymphomas accounting for approximately $70 \%$ of cases [5]. Approximately $5 \%$ to $10 \%$ of cases are idiopathic, but in most of these cases, an occult neoplasm is found to be the culprit eventually [6].

No cases in association with RCC have been reported in the literature and to the best of our knowledge, this is the first reported case of chylothorax secondary to RCC. We theorize that the compression of the thoracic duct below T 5 by the right-sided RCC resulted in the formation of the chylothorax in our patient. This is further supported by the fact that after microwave ablation of the RCC in our patient, the chylothorax did not recur.

\section{Conclusions}

In some patients, chylothorax may be the initial presentation of an occult malignancy. Therefore, it is critical that all patients presenting with chylothorax and no history of trauma or recent surgery should undergo extensive work-up to look for the underlying cause, as it may be the first manifestation of an underlying malignancy as seen in this case. 


\section{Cureus}

\section{Additional Information}

\section{Disclosures}

Human subjects: Consent was obtained by all participants in this study. Conflicts of interest: In compliance with the ICMJE uniform disclosure form, all authors declare the following: Payment/services info: All authors have declared that no financial support was received from any organization for the submitted work. Financial relationships: All authors have declared that they have no financial relationships at present or within the previous three years with any organizations that might have an interest in the submitted work. Other relationships: All authors have declared that there are no other relationships or activities that could appear to have influenced the submitted work.

\section{References}

1. Weidner WA, Steiner RM: Roentgenographic demonstration of intrapulmonary and pleural lymphatics during lymphangiography. Radiology. 1971, 100:533-539. 10.1148/100.3.533

2. Maldonado F, Hawkins FJ, Daniels CE, Doerr CH, Decker PA, Ryu JH: Pleural fluid characteristics of chylothorax. Mayo Clin Proc. 2009, 84:129-133.

3. Staats BA, Ellefson RD, Budahn LL, Dines DE, Prakash UB, Offord K: The lipoprotein profile of chylous and nonchylous pleural effusions. Mayo Clin Proc. 1980, 55:700-704.

4. Doerr CH, Allen MS, Nichols FC III, Ryu JH: Etiology of chylothorax in 203 patients . Mayo Clin Proc. 2005, 80:867-870. 10.4065/80.7.867

5. Nair SK, Petko M, Hayward MP: Aetiology and management of chylothorax in adults . Eur J Cardiothorac Surg. 2007, 32:362-369. 10.1016/j.ejcts.2007.04.024

6. McWilliams A, Gabbay E: Chylothorax occurring 23 years post-irradiation: literature review and management strategies. Respirology. 2000, 5:301-303. 10.1046/j.1440-1843.2000.00263.x 